Article

\title{
Transnational Municipal Climate Networks and the Politics of Standardisation: The Contested Role of Climate Data in the New Global Covenant of Mayors for Climate and Energy
}

\author{
Friederike Gesing \\ artec Sustainability Research Center, University of Bremen, 28334 Bremen, Germany; E-Mail: f.gesing@uni-bremen.de
}

Submitted: 20 July 2017 | Accepted: 23 October 2017 | Published: 25 September 2018

\begin{abstract}
This article analyses the formation of a new global network, the Global Covenant of Mayors for Climate \& Energy (GCoM), by two existing initiatives, the EU-based Covenant of Mayors and the UN-supported Compact of Mayors. While this merger of two transnational networks provides evidence for the increased coordination and standardisation of transnational municipal climate action, this remains a contentious and incomplete process. The article identifies different modes of transnational climate governance that have contributed to conflict between the founding networks and zooms in on the role of municipal climate data. Using empirical evidence, it analyses the contested politics of municipal climate data, including the role of the Global Protocol for Community-Scale Greenhouse Gas Emission Inventories (GPC) as a standard tool, the definition of a common target, and the inclusion of financial actors. Concerns over the reshaping of public-private boundaries and the possible commodification of public data are identified as major obstacles for the (EU) Covenant of Mayors, which consequentially seeks to remain as independent as possible within the new GCoM. Data politics emerges as a crucial factor for the future direction of transnational municipal climate policy and the ongoing processes of standardisation and coordination.
\end{abstract}

\section{Keywords}

cities and climate change; Compact of Mayors; Covenant of Mayors; Global Covenant of Mayors for Climate and Energy; Global Protocol for Community-Scale Greenhouse Gas Emission Inventories; multi-level governance; municipal climate data; standardisation practices; transnational climate governance; transnational municipal networks

Issue

This article is part of the issue "Multidisciplinary Studies" in Politics and Governance.

(C) 2018 by the author; licensee Cogitatio (Lisbon, Portugal). This article is licensed under a Creative Commons Attribution 4.0 International License (CC BY).

\section{Introduction: Transnationalising Municipal Climate Action}

Non-state actors have gained increasing recognition in global climate policy in recent years (Fuhr \& Hickmann, 2016; Pattberg \& Widerberg, 2015). The decision to adopt the Paris Agreement for the first time explicitly "welcomes the efforts of all non-Party stakeholders to address and respond to climate change" (United Nations Framework Convention on Climate Change [UNFCCC], 2016, p. 19). The international process has taken a "shift away from Kyoto-style top-down regulations" towards a "decentralized, bottom-up process of voluntary pledges" (Falkner, 2016, p. 1114). Non-state ac- tors are a key feature of this "new catalytic and facilitative climate regime" (Hale, 2016, p. 13) and seek to actively intervene in the global arena (Bulkeley et al., 2014, p. 1). Transnational climate governance (TCG) consists of activities undertaken by "stakeholders other than States that are party to the UNFCCC", including cities, regions, corporations, civil society groups, and investors (Chan, Brandi, \& Bauer, 2016, p. 240). While cities and city networks have long been vocal stakeholders of TCG (Bulkeley, Castán Broto, \& Edwards, 2012), an increasing degree of coordination and standardisation of municipal responses to climate change has been observed recently (Bulkeley, 2015). The formation of the new Global Covenant of Mayors for Climate and Energy (GCoM) is 
a prime example of this trend. In January 2017, the EUbased Covenant of Mayors ${ }^{1}$ and the UN-supported Compact of Mayors formally joined forces under the umbrella of the GCoM. However, the merger remains a contentious and incomplete process. This article asks whether the politics of standardisation inherent in this merger are also responsible for the difficulties encountered. It uses empirical evidence: participant observation at the COP 21, document analysis and interviews. ${ }^{2}$ Section 2 scrutinises the different political modes developed by the Covenant of Mayors and the Compact of Mayors. The Covenant of Mayors has focused on establishing a new TCG structure which links municipalities to a common target for emission reductions, whereas the Compact of Mayors has developed a data-based approach to municipal climate action, building on the Global Protocol for Community-Scale Greenhouse Gas Emission Inventories (GPC) introduced as a standard tool. Section 2.3 discusses these different political modes in relation to the formation of the GCoM. Section 3 then zooms in on conflicts over the politics of standardization that emerged in the negotiations about the GCoM. It analyses the role of municipal climate data by looking at discussions about the future use of the GPC by the GCoM, the inclusion of financial actors, and the suggestion to define a common target. In the conclusion, concerns over the reshaping of public-private boundaries are identified as the main obstacle for further integration, most visible in concerns over the possible commodification of public data voiced by the Covenant of Mayors, which consequentially seeks to remain as independent as possible within the GCOM.

\section{Conflicting Modes of Transnational Climate Action}

\subsection{The Covenant of Mayors: Multi-Level Climate Governance in Practice}

The Covenant of Mayors was launched by the European Commission in 2008 to foster the implementation of sustainable energy policies at local authority level. It is managed through the Covenant of Mayors Office (CoMO) by a consortium of European city networks (Energy Cities, CEMR, Climate Alliance, EUROCITIES and FEDARENE) acting as supporting members, with funding provided by the Commission. Signatories commit to meet the goals of the EU common climate and energy policies as initially defined by the 2020 Climate and Energy Package. Since 2015 , signatories have committed to achieving at least a $40 \%$ reduction in $\mathrm{CO} 2$ emissions by the year 2030 , as agreed upon in the EU 2030 Framework for Climate and Energy (Covenant of Mayors [CoM], 2015a). Kona et al. $(2016$, p. 39) estimate the emission reductions resulting from these commitments as being $254 \mathrm{Mt} \mathrm{CO2-eq} \mathrm{by}$ 2020. Commitments are reported in the form of Sustain- able (Climate) Actions Plans (SEAP/SECAP); failure to submit these plans leads to membership suspension.

The CoM "despite its name, was never just a covenant of mayors" (Interview Callestere, 4 December 2016)-because the involvement of territorial and regional authorities has been crucial to coordinate and support cities and municipalities. The Covenant of Mayors, therefore, claims to be "built upon a unique multi-level governance model" (CoM, 2015a). By putting multi-level governance into practice, the Covenant of Mayors has produced new relationships:

The provinces and regions have found a new role through the Covenant of Mayors and developed it further. They discovered a new way of working with the municipalities that did not exist before.....For these institutions, the Covenant of Mayors is an asset as well, because it gave them possibilities they did not have before. And [now] they speak with municipalities about investments, about street lightening, urban planning, traffic, energy policy, sanitation. And they do not speak with one municipality separately, but with hundreds of municipalities at the same time. (Interview Gheorghe, 28 June 2016)

Stimulating such multilevel practices of knowledge exchange and administrative support, the Covenant of Mayors has the larger vision of being a "mainstream EU policy instrument" (CoM, 2015a). In this vein, it is defined as an explicitly political tool with far-reaching effects:

It is neither a programme nor a project but a political endeavour, with Mayors putting the new EU commitment to the approval of their municipal councils. It encourages multi-level cooperation between various government levels, from small villages to provinces, regions, national bodies and $\mathrm{EU}$ institutions. It combines bottom-up legitimacy with institutional credibility. (CoM, 2015b)

These mechanisms for assuring democratic legitimacy and cooperation between various administrative levels produce multi-level governance in practice (Bulkeley \& Betsill, 2013). Through these practices, a shared understanding of the Covenant of Mayors as being "bottomup" has emerged among the member community, even though it was initiated from the top, by the European Commission. Understood as forging productive relations between levels of governance, the Covenant of Mayors puts the central principles of European governancesubsidiarity and multi-level governance-into practice. However, the foundation of the Compact of Mayors in 2014 triggered internal discussions within the Covenant of Mayors regarding whether it should also be developed into an explicitly international initiative, "be-

\footnotetext{
${ }^{1}$ In order to avoid confusion, "Covenant of Mayors" will be used to denominate the initiative that was founded under this name in 2008 , and renamed "Covenant of Mayors for Climate and Energy" in 2015 (CoM, 2015a).

2 The pseudonyms of the interview partners are found in the Annex.
} 
cause it became clear, if the [European] Commission doesn't do it, others will be doing it" (Interview Gheorghe, 28 June 2016). ${ }^{3}$ In 2015, the Climate Alliance network-a Covenant supporter-suggested to "export the Covenant worldwide" (Climate Alliance, 2015, p. 5). The formation of the GCoM, however, has been fostered mainly by the Compact of Mayors and has confronted the Covenant of Mayors with a decidedly different approach to transnational climate policy.

\subsection{The Compact of Mayors: A Data Approach to Transnational Municipal Climate Action}

The Compact of Mayors was founded at the 2014 UN Climate Summit by Michael R. Bloomberg, UN Special Envoy for Cities and Climate Change and former Mayor of New York City, in cooperation with the city networks C40 Cities Climate Leadership Group (C40), Local Governments for Sustainability (ICLEI), the United Cities and Local Governments (UCLG), and the United Nations Human Settlements Programme (UN-Habitat). 621 cities have committed to the Compact of Mayors prior to the start of 2017 which represents " $6.72 \%$ of the total global population", according to its website. The Compact of Mayors has been laid out as an explicitly global initiative. Its ambition to claim global leadership in municipal climate action was underlined in 2015 by Ban-Ki Moon's call for all cities in the world to join the Compact of Mayors (Bloomberg Philanthropies, 2015b). The Compact follows a four-step approach to compliance in which cities sign the Compact, conduct an emission inventory using the Global Protocol for Community-Scale Greenhouse Gas Emission Inventories (GPC), then define an individual target and finally work out an action plan to reach it. Inventories and commitments have to be publicly shared (Compact of Mayors, 2015). Signatories who have accomplished one of the four steps can keep their status even if they fail to reach the next step, e.g. signing the Compact of Mayors, but not conducting an emission inventory. The Compact of Mayors has not prescribed a common target; signatories choose their commitment as well as the baseline year of their emission inventory. In November 2016, 596 commitments made by Compact cities equalled nearly one billion tons of greenhouse gas emissions savings annually by 2030 (Global Covenant of Mayors [GCoM], 2016b).

The GPC is a tool for the standardisation of municipal emission data which has been developed by the founders of the Compact of Mayors (World Resources Institute, C40, \& ICLEI, 2015). Reference to the GPC underlines the political ambition of the Compact of Mayors to provide better recognition and funding opportunities for city-level climate action by introducing a "single, consistent metric for city climate impact" (Compact of Mayors, n.d.). The reporting mechanism is said to make sure that:

everyone in the world can understand what is happening in their city, and they're all using the same metrics so that at the end of the day, we can add up everything from every compliant city and understand just how important city action is. (IISD, 2015)

This argument asserts that a common metric for urban emission data directly translates into a measurement of urban climate action-a strong political argument for transnational municipal climate policy based on emission measurement and management: "If you can't measure it, you can't manage it and you can't fix it", as Michael R. Bloomberg expressed on Twitter (21 January 2014). The GPC should also facilitate private sector investment:

For the first time, the Compact will standardize the way city climate data is reported, establishing a universal approach to data collection. The data can be aggregated to highlight the collective impact of city actions, which will increase global and investor confidence. (Compact of Mayors, 2015)

This ambition is evidence to both the increasing focus on standard schemes and to the rising activity of private actors in TCG as observed by Roger, Hale and Andonova (2017). It also shows the ongoing blurring of the public-private boundary in the practices of transnational municipal climate action (Castán Broto \& Bulkeley, 2013). The Compact of Mayors is administered and, in the main, funded by Bloomberg Philanthropies, a charitable foundation created by Bloomberg to bundle his personal and corporate giving. Its "unique data-driven approach to global change" is attributed to Bloomberg's "experience as an entrepreneur and a champion of innovation" (Bloomberg.org Group, 2017). Summing up, the Compact of Mayors can be characterised as a player with global aspirations, consolidating TCG with reference to the standardisation of municipal emission data. The Compact of Mayors now brings this agenda to the GCoM, including its objective to promote the GPC as a standard protocol for cities.

\subsection{Visions for the GCoM: Cities, Mayors and the Production of Transnational Authority}

The Covenant of Mayors and the Compact of Mayors have established different practices for producing authority which they both brought to the GCoM negotiation table. The Covenant of Mayors claims to have built a new governance model that binds cities directly to European climate policy. Since it received its mandate from the European Commission (and thereby indirectly also from the

\footnotetext{
${ }^{3}$ Regardless of the link to EU policy, many of the more than 6,000 member communities are from non-EU countries, located in the Eastern and Southern neighbourhood, or as far away as Argentina or New Zealand. Considerations to actively enlarge the initiative beyond the EU could further build on the experience of the European Commission with two earlier projects that supported cities in Eastern and Southern neighbourhood countries of the EU to join the Covenant of Mayors, CoM-East and CES-MED (CoM, 2016b).
} 
EU member states), it makes a claim to "delegated authority...ultimately derived from the state" (see Green, 2014, p. 7). The Covenant of Mayors continues to draw upon the political and institutional authority of the EU, even in the process of designing structures for the GCoM. A newly founded European Covenant of Mayors Board will oversee the former Covenant of Mayors signatories in the shape of a Regional European Covenant within the GCoM. The board should "reaffirm the initiative as a unique political movement steered by mayors", aiming to further facilitate the "dialogue between the European Covenant community and the EU institutions" (CoM, 2017).

The Compact of Mayors defines the agency of cities in a more direct way since it does not emphasise their relation to any larger structure. Instead, it builds strongly on the idea of mayors and their networks as "global governors" (Avant, Finnemore, \& Sell, 2010). Barber (2013, p. 11) argues that transnational municipal networks (TMN) are often created by strong leaders such as Michael R. Bloomberg building on a "pragmatic, problemsolving" approach. The symbolic value of (mayoral) leadership implied in the "Bloomberg approach" is showcased by a video documenting the Paris Climate Summit for Local Leaders held during the COP 21 in 2015. It argues that "mayors are being closer to the people, and closer to the ground, and less political" (Bloomberg Philanthropies, 2015a). This statement (voiced by Compact of Mayor celebrity guest Robert Redford) feeds into a discourse about cities being more effective and actionoriented than states.

This provides a stark contrast to understanding cities as strong players exactly because they are integrated into different levels of politically legitimised governments. The European Commission representative insists that mayors are indeed political actors, and that "one of the differences between mayors and national governments is that the mayors try to work in a very political way in cooperation, while the national governments try to work in competition" (Callestere, 4 December 2016). His vision of the GCoM is that cities and subnational governments "all over the world are acting as smoothers in the relations between national governments...[in] an initiative that is making of climate change the best for peaceful cooperation. Instead of as is the case now, a vector for conflict" (Callestere, 4 December 2016). Callestere sees this vision of cooperation endangered by the figure of Bloomberg himself, whom he characterises as "a very competitive guy" - in his business approach and during his tenure as Mayor of New York City. Barber (2013, p. 25) argues in the same vein when describing Bloomberg's "business approach to problem-solving":

He's all business and not enough politics.... Bloomberg incarnates the idea that mayors are practical rather than ideological, bridging politics and business with a non-politics of practical science and numbers....As a result, Bloomberg trades in successful outcomes rather than in democratic legitimacy. (Barber, 2013, p. 26)
Possibly "changing the terms of the debate" (Green, 2014 , p. 20), the establishment of new modes of action by a powerful actor such as the Special Envoy for Cities and Climate Change Michael R. Bloomberg has the potential to shape the future form of TCG. Municipal climate data plays a particularly important role in the ongoing standardisation of transnational municipal climate action (Bulkeley, 2015). As shown in section 2.2, it has already featured prominently in the strategies of the Compact of Mayors. It is therefore not surprising that data issues have emerged as crucial points of discussion in the negotiations over the merger. The following section will focus on the contested role of municipal climate data in the formation of the GCoM.

\section{The Formation of the GCoM and the Politics of Standardising Municipal Climate Data}

In the process of forming the GCoM, significant struggles over the politics of municipal climate data have become evident. They occur in the context of a developing discourse that reclaims more visibility for urban climate policy on the international stage by reference to municipal emission data. Bulkeley criticises the increasing dominance of accounting approaches which rely on "a model of urban climate governance in which growing evidence (e.g. on emissions and on risks) informs a policy agenda...that can be readily accounted for and verified" (Bulkeley, 2015, p. 1408). This model of transnational municipal climate governance is built on the production of comparable data, and hence the introduction of standard tools for accounting municipal emissions. Higgins and Larner insist that "the variety of techniques and practices-such as standards, benchmarking, auditing systems and forms of accounting" that enable transnational governance demand critical attention by social scientists $(2010$, p. 9). Some form of standardisation is the prerequisite for almost any social, legal or economic interaction or political decision-making. Lampland and Star argue that since "standardization is considered to be a necessary technique designed to facilitate other tasks...the process of standardization is both a hidden and a central feature of modern social and cultural life" $(2009$, p. 10). Standards are not intrinsically good or bad; however, their proliferation reflects late modern political rationalities and potentially privileges technocratic approaches. Standardisation is a social practice, a technology of governing (Higgins \& Larner, 2010). Mattli and Büthe describe the first mover advantage evident in the introduction of new standards, where "first movers set the international standards agenda, and laggards, or second movers, pay the switching costs" (2011, p. 4). The case study presented here concentrates on the dynamic processes of agenda-setting as a reconfiguration of TCG in which the standardisation of municipal emission accounting emerges as a central issue.

Not merely a technocratic solution, municipal emission accounting is also a specific approach to transna- 
tional governance. Bulkeley et al. (2014) point to the proliferation of emission reporting standards across private and public actors, arguing that such "take-up by other institutions of TCCG [transnational climate change governance] rules and practices is also a useful way to think about the effects (or even effectiveness) of TCCG initiatives" (Bulkeley et al., 2014, p. 157) in a more procedural way, which is interested into the general reconfiguration of transnational climate action. Importantly, in the processes and practices of standardising TCG, "takenfor-granted dichotomies such as global and local, state and market, public and private...emerge out of complex articulations between actors in multiple locations" (Higgins \& Larner, 2010, p. 10). This mirrors the observation by Bulkeley and Schroeder (2011) that such attributes should not be treated as essential properties since private actors increasingly take over public functions and public actors use private market mechanisms.

This means that standardisation processes themselves are productive; they produce and reproduce transnational relations. At the same time, standards function as "fact factories". According to Dunn, "by specifying particular forms of data collection, recording, and analysis, they act as engines for generating knowledge about products, processes, and people" (2005, p. 184). In the process of merging the Covenant of Mayors and the Compact of Mayors, the question whether the standardisation of municipal climate data should indeed form the basis of the future GCoM emerged as a contested issue. The two merging initiatives were built on different political strategies and motives for merging. The UNsupported Compact of Mayors has already strived to become a universal representative of urban climate action on the global scale, while the European Commissionthe initiator of the Covenant of Mayors-argued that as a public servant, it had to work towards a single initiative in order to provide clarity for the cities. The remainder of this article addresses the struggles over the role of the GPC, and over the definition of a common target for the GCoM as being facets of an unfolding controversy regarding the politics of municipal climate data and the future role of standardisation practices in transnational municipal climate governance.

\subsection{Towards an Accounting Framework: Struggles over the GPC as Common Tool}

The Compact of Mayors' demand to establish the GPC as a single standard for GCOM signatories has been a hot topic in the negotiations (Interview Torres, 11 October 2016). While the GPC was eventually defined as the official tool of the GCoM, the Covenant of Mayors' signatories continue to use their own established methods (CoM, 2016a), as doubts still remain regarding compatibility (I. Gheorghe, personal communication, 5 April 2017). For cities that have already conducted emission inventories, switching to the GPC simply for the sake of comparability would require recalculation of all existing inventories back to the baseline year in order to keep the internal comparison within a city intact-incurring a considerable switching cost without added value (Gus, 18 August 2016). For the time being, existing commitments to either the Covenant of Mayors or the Compact of Mayors will remain valid over a two-year transition period (GCoM, 2017).

From the side of the Covenant of Mayors, there is also general concern that the "Bloomberg approach" equals establishing a direct link between GHG emissions and funding opportunities, with the intention to demonstrate "how many emissions do we manage, and how many funds can we get for them" (Interview Gheorghe, 28 June 2016). While municipalities need funding for climate projects, as the interview partner readily admits, she is concerned about putting the administration of such funds into private hands and is wary of the connection between Bloomberg's business interests and his engagement in the GCoM. While Bloomberg's reputation as a successful self-made businessman has been positively drawn upon in Compact of Mayor campaigns, it does not facilitate trust in the European context-on the contrary. The senior European Commission representative responsible for negotiating with the Compact of Mayors over the details of the GCoM found it pivotal to prevent the introduction of the GPC as mandatory tool for the GCoM, stressing that "of course we are not going to follow a commercial methodology, imposed by Mr Bloomberg" (Interview Callestere, 4 October 2016).

These concerns are supported by the observation that the Compact of Mayors has a history of advertising the GPC as "the protocol that private investors, national governments, and the broader global community will be utilising to quantify, compare and aggregate the impact of local climate action" (Compact of Mayors, n.d.). From the perspective of the Covenant of Mayors and the European Commission, financial investors constitute a new class of actors that has been written into the GCoM. GHG emission data are not only used to underline the importance of transnational municipal climate policy visà-vis national players, but also advertised as "giving investors the ability to see that the actions cities have been taking are having lasting, verifiable, and most importantly, investable impact" (GCoM, 2016a, emphasis in original). There is concern that this means public urban climate data could be used to develop privately marketable services:

The problem with data...is that when you have data, you can manage the data, you can trade data....And one of the major objectives of $\mathrm{Mr}$ Bloomberg is...financial data. And now he would like to have, and he's not hiding it, something huge on public procurement data...if you are able, with a good algorithm, to manage public data...on the planned investments of a high number of cities in the next years, you can inform very powerful companies all over the world on the public procurement prospects. You can give 
them precious information that is going to help them to device their deeds, their public-private investment schemes....And this is a big business, if people would pay for that. (Interview Callestere, 4 October 2016)

This statement describes irritation over the re-shuffling of public-private boundaries taking place under the conditions of the GCoM. Concern regarding the possibility of public information being turned into a commodity is underlined by the Covenant of Mayors' understanding of transnational municipal climate policy, which stresses the need to respect existing local political processes and account for the distribution of power over different existing levels of governance:

Cities, all over the world...have partial competences. So data is not so important because you don't know if this data refers to the geographical space in which the city has a partial competence, or to the competences of the city...it's very important also to understand how the countries are structured, who can do what. This is for me far more important than data. (Interview Callestere, 4 October 2016)

Callestere eventually brings forward these doubts regarding data management by advocating for the Covenant of Mayors to remain a separate entity within the GCoM. While the data concerned here might not be particularly sensitive, the commissioner has voiced his clear opposition to the idea of turning publicly sourced data into a tradable commodity, which he understands as being "a transfer of power, a transfer of information". From his point of view, the dominant role of municipal climate data in the formation of the GCoM in general amounts to a fundamental shift from a political to an accounting framework:

For me, at the time [when the merger was first discussed], data was something that was not the crucial thing...for me, the important thing was the political commitment to build trust, between the cities, and the other subnational institutions on this. It was a very political approach....This has been...changed by an...approach very much based up on collection of data, and management of data. (Interview Callestere, 4 October 2016)

Concluding from this statement, the shifting politics of municipal climate data can be said to play an absolutely central role in the negotiations and the ensuing conflict over the formation of the GCoM.

\subsection{An Alternative Political Framework: Defining a Common Target}

While the Compact of Mayors has promoted the introduction of the GPC as the common GCoM tool, the Covenant of Mayors has instead advocated the definition of a common target. The European Commission representative explains that he had originally suggested defining a strict common long-term target for all GCoM members. He frames this proposal in terms of reaching climate justice:

That was for me the most important thing, to have something that is shared in the very long-term basis, in which all the injustices of the past, all the historic responsibilities, are already embedded in this common objective. And there you need to be very strict...you need to have only one objective for everybody. Otherwise, it doesn't work. Because you would be perpetuating the differences, [the] different political and economic terms. (Interview Callestere, 4 October 2016)

The suggestion for there being a common target was rejected, and the GCoM eventually established the nationally determined contributions (NDCs) pledged by nation states under the Paris Agreement as minimum targets for cities in their respective territories. This produces a great variety of individual targets. For Callestere, a common target would have been necessary to eventually achieve climate justice and fair conditions for cities in very different situations. On the other hand, he sees the comparative data approach as counterproductive, because it measures the wrong things and directs resources away from the most pressing issues. In his opinion, emission data is not immediately politically relevant in Global South contexts, where adaptation or access to energy is of much greater immediate importance. "How can you tell the people in Mumbai...to use their very scarce resources in order to produce very expensive plans that go nowhere, with a lot of data that is important for [very few] people", he asks rhetorically (Interview Callestere, 4 October 2016). Carbon data alone has no effect on these further political goals, which is why he perceives the emphasis on GHG emissions data as a stand-in for climate action as problematic. On a more general level, the Covenant of Mayors defines the setting of emission goals as a political act to be approved by city councils, and not merely a technocratic management decision (Interview Gus, 18 August 2016).

\section{Conclusions}

The contentious process of forming the GCoM provides a window into the potentially far-reaching political effects of the "pragmatic, problem-solving approach" brought to the global agenda of climate governance by transnational climate action (Hale, 2016, p. 20). The formation of the GCoM is evidence of a strategic moment in TCG, characterised by the increasing recognition of municipal climate action in the international arena, and by ongoing efforts to further coordinate and standardise urban climate action (Bulkeley, 2015). As part of this process, standardised municipal emission reporting has gained increasing political power. Pushing to introduce the GPC 
as a common metric for the new network, the Compact of Mayors has attempted to rearrange the field of TCG around the GPC as an "obligatory passage point" (Wilmsen \& Gesing, 2016, p. 34, following Callon, 1986). The Covenant of Mayors, on the other hand, has refused to accept the GPC as a common tool, instead arguing for common long-term targets. Policy targets such as general access to clean energy, as well as GHG emission reduction targets are both understood as contributions to achieve long-term climate goals, and therefore as politically productive.

The Compact of Mayor's focus on producing comparable municipal emission data was met with concern by the Covenant of Mayors over the potential for municipal emissions becoming commodified, up for taking by private investors. This irritation over the data approach, and over the role of Michael R. Bloomberg as a powerful political and economic figure, reflects different implicit understandings of how trust and political commitment might be built. Two "completely different principles" (Callestere, 4 October 2016) have been at work here, expressed in two contrasting modes of transnational municipal climate policy, one relying on quantitative data and individual leadership, the other building on bottom-up, democratic legitimisation and service to the public. The ensuing conflict goes to the heart of what Castán Broto and Bulkeley (2013) have described as the re-ordering of the public and the private in transnational municipal climate policy, played out here in the struggles over the role of municipal emission data. The insistence on the protection of public data against private financial interests, used as a strong argument against the "Bloomberg approach" from the side of the European Covenant of Mayors, can be understood as a way of packaging resistance against this ongoing reshaping of the public and private spheres.

\section{Acknowledgments}

Work on this article has been supported by Stiftung Mercator in the scope of ZenTraClim, a joint initiative by Stiftung Mercator, the Carl von Ossietzky University Oldenburg and the University of Bremen. Publication has been funded by the University Library of Bremen via the DFG open access publishing program. I would like to thank Ina Lehmann, Michael Flitner, Heiko Garrelts and the anonymous reviewers for their careful reading, valuable comments and suggestions.

\section{Conflict of Interests}

The author declares no conflict of interests.

\section{References}

Avant, D. D., Finnemore, M., \& Sell, S. K. (2010). Who governs the globe? In D. D. Avant, M. Finnemore, \& S. K. Sell (Eds.), Who governs the globe? (pp. 1-32). Cam- bridge: Cambridge University Press.

Barber, B. R. (2013). If mayors ruled the world: Dysfunctional nations, rising cities. New Haven, CT: Yale University Press.

Bloomberg Philanthropies. (2015a). Highlights from the climate summit for local leaders. Youtube. Retrieved from https://www.youtube.com/watch? $\mathrm{v}=\mathrm{iQshhCBIk8Q}$

Bloomberg Philanthropies. (2015b). Global Impact of the Compact of Mayors. Youtube. Retrieved from https://www.youtube.com/watch?v=OSaAeWVmuJs

Bloomberg.org Group. (2017). Mike Bloomberg. bloomberg.org. Retrieved from https://www.bloom berg.org/about/mike-bloomberg

Bulkeley, H. (2015). Can cities realise their climate potential? Reflections on COP21 Paris and beyond. Local Environment, 20(11), 1405-1409.

Bulkeley, H., Andonova, L. B., Betsill, M. M., Compagnon, D., Hale, T., Hoffman, M. J., . . . Vandeveer, S. D. (Eds.). (2014). Transnational climate change governance. Cambridge: Cambridge University Press.

Bulkeley, H., \& Betsill, M. M. (2013). Revisiting the urban politics of climate change. Environmental Politics, 22(1), 136-154. doi:10.1080/09644016.2013.755797

Bulkeley, H., Castán Broto, V., \& Edwards, G. (2012). Bringing climate change to the city: Towards low carbon urbanism? Local Environment, 17(5), 545-551. doi:10.1080/13549839.2012.681464

Bulkeley, H., \& Schroeder, H. (2011). Beyond state/nonstate divides: Global cities and the governing of climate change. European Journal of International Relations, 18(4), 743-766. doi:10.1177/ 1354066111413308

Callon, M. (1986). Some elements of a sociology of translation: Domestication of the scallops and the fishermen of St Brieuc Bay. In J. Law (Ed.), Power, action and belief: A new sociology of knowledge? (pp. 196-223). London: Routledge.

Castán Broto, V., \& Bulkeley, H. (2013). A survey of urban climate change experiments in 100 cities. Global Environmental Change, 23(1), 92-102. doi:10.1016/ j.gloenvcha.2012.07.005

Chan, S., Brandi, C., \& Bauer, S. (2016). Aligning transnational climate action with international climate governance: The road from Paris. Review of European, Comparative \& International Environmental Law, 25(2), 238-247. doi:10.1111/reel.12168

Climate Alliance. (2015). Five key recommendations for the second generation of the Covenant of Mayors. Brussels: Climate Alliance.

Covenant of Mayors for Climate and Energy. (2015a). Q\&As for cities. Merging climate change mitigation (Covenant of Mayors) and adaptation (Mayors Adapt) under one single umbrella initiative (Covenant of Mayors for Climate \& Energy)-What does this mean in practice? Brussels: Covenant of Mayors for Climate and Energy.

Covenant of Mayors for Climate and Energy. (2015b). 
2015 ceremony: The new integrated Covenant of Mayors on Climate and Energy. Brussels: Covenant of Mayors for Climate and Energy.

Covenant of Mayors for Climate and Energy. (2016a). The Covenant of Mayors for Climate and Energy reporting guidelines. Brussels: Covenant of Mayors for Climate and Energy.

Covenant of Mayors for Climate and Energy. (2016b). The Covenant of Mayors going global. Covenant of Mayors for Climate and Energy. Retrieved from http://www.covenantofmayors.eu/The-Covenant-ofMayors-going,2332.html

Covenant of Mayors for Climate and Energy. (2017). A Board of Mayors to steer the largest community of cities committed to the EU climate and energy objectives [Press release]. Brussels: Covenant of Mayors for Climate and Energy.

Compact of Mayors. (n.d.). Compact of Mayors - FAQ for US local governments. New York, NY: Compact of Mayors.

Compact of Mayors. (2015). Compact of Mayors (full guide). New York, NY: Compact of Mayors.

Dunn, E. (2005). Standards and person-making in East Central Europe. In A. Ong \& S. J. Collier (Eds.), Global assemblages (pp. 174-193). Malden, MA: Blackwell Publishing.

Falkner, R. (2016). The Paris Agreement and the new logic of international climate politics. International Affairs, 92(5), 1107-1125. doi:10.1111/1468-2346.12708

Fuhr, H., \& Hickmann, T. (2016). Transnationale Klimainitiativen und die internationalen Klimaverhandlungen [Transnational climate initiatives and the international climate negotiations]. Zeitschrift für Umweltpolitik \& Umweltrecht, 2, 88-94.

Global Covenant of Mayors for Climate and Energy. (2016a). "Charter" for the Global Covenant of Mayors for Climate and Energy. Retrieved from http://www. globalcovenantofmayors.org/wp-content/uploads/ 2016/06/Charter-for-the-Global-Covenant-of-Mayors -for-Climate-and-Energy-FINAL.pdf

Global Covenant of Mayors for Climate and Energy. (2016b). The Global Covenant of Mayors for Climate \& Energy announces its global impact [Press release]. Retrieved from http://www.globalcovenantof mayors.org/press/global-covenant-mayors-climateenergy-announces-collective-impact-cities-moveparis-agreement-commitment-action

Global Covenant of Mayors for Climate and Energy. (2017). Global Covenant of Mayors for Climate \& Energy Technical FAQ. Retrieved from http://www. globalcovenantofmayors.org/wp-content/uploads/ 2017/10/2017-10-17-GCoM-FAQ.pdf

Green, J. F. (2014). Rethinking private authority agents and entrepreneurs in global environmental governance. Princeton, NJ: Princeton Univ. Press.

Hale, T. (2016). "All hands on deck": The Paris Agreement and nonstate climate action. Global Environmental Politics, 16(3), 12-22. doi:10.1162/GLEP_a_00362

Higgins, V., \& Larner, W. (2010). Calculating the social: Standards and the reconfiguration of governing. Houndmills, Basingstock, Hampshire and New York, NY: Palgrave Macmillan.

IISD. (2015). Compact of Mayors: The world's largest coalition on local climate action and towards sustainable development goals/HABITAT III. Vimeo. Retrieved from https://vimeo.com/148218115

Kona, A., Melica, G., Koffi, B., Iancu, A., Zancanella, P., \& Rivas Calvete, S. (2016). Covenant of Mayors: Greenhouse gas emissions achievements and projections. Luxembourg: Publications Office of the European Union.

Lampland, M., \& Star, S. L. (2009). Standards and their stories: How quantifying, classifying, and formalizing practices shape everyday life. Ithaca, NY: Cornell University Press.

Mattli, W., \& Büthe, T. (2011). Setting international standards: Technological rationality or primacy of power? World Politics, 56(1), 1-42. doi:10.1353/wp. 2004.0006

Pattberg, P., \& Widerberg, O. (2015). Theorising global environmental governance: Key findings and future questions. Millennium-Journal of International Studies, 43(2), 684-705. doi:10.1177/ 0305829814561773

Roger, C., Hale, T., \& Andonova, L. (2017). The comparative politics of transnational climate governance. International Interactions, 43(1), 1-25. doi:10.1080/ 03050629.2017 .1252248

United Nations Framework Convention on Climate Change. (2016). Report of the conference of the parties on its twenty-first session, held in Paris from 30 November to 13 December 2015. UNFCCC. Retrieved from http://climateaction.unfccc.int/about

Wilmsen, F., \& Gesing, F. (2016). The Global Protocol for Community-Scale Greenhouse Gas Emission Inventories (GPC) $-A$ new passage point on an old road? (ZenTra Working Paper in Transnational Studies No. 68). Bremen: Center for Transnational Studies (ZenTra).

World Resources Institute, C40, \& ICLEI. (2015). Global Protocol for Community-Scale Greenhouse Gas Emission Inventories: An accounting and reporting standard for cities. Retrieved from http://www.ghg protocol.org/sites/default/files/ghgp/standards/GH GP_GPC_0.pdf 


\section{About the Author}

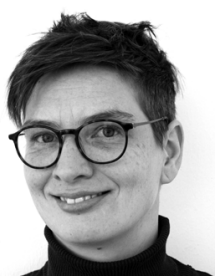

Friederike Gesing is a postdoctoral researcher at the artec Sustainability Research Center, University of Bremen and co-founder of the Bremen NatureCultures Lab (www.naturenkulturen.de). She is the author of Working with Nature in Aotearoa New Zealand-An Ethnography of Coastal Protection (transcript, 2016). She has been a fellow with the Science, Technology and Society (STS) Program at Harvard University, and undertook dissertation research in the international research training group INTERCOAST (Integrated Coastal Zone and Shelf-Sea Research) at the University of Bremen and the University of Waikato. 
Annex

\section{Interview Partners (Pseudonyms)}

Jean Callestere, European Commission / Covenant of Mayors for Climate Energy, 4 October 2016. losefina Gheorghe, Covenant of Mayors for Climate Energy, 28 June 2016.

Victor Gus, Covenant of Mayors for Climate Energy, 18 August 2016.

Antonia Torres, ICLEI / Compact of Mayors, 11 October 2016 